\title{
Kinetic Studies on the Inactivation of L-Lactate Oxidase by [the Acetylenic Suicide Substrate] 2-Hydroxy-3-butynoate ${ }^{\dagger}$
}

\author{
Sandro Ghisla, ${ }^{\ddagger}$ Hatenori Ogata, $\S$ Vincent Massey, Agnes Schonbrunn, \# \\ Robert H. Abeles,* and Christopher T. Walsh
}

\begin{abstract}
Hydroxy-3-butynoate is both a substrate and an irreversible inactivator of the flavoenzyme L-lactate oxidase. The partitioning between catalytic oxidation of 2-hydroxy3-butynoate and inactivation of the enzyme is determined by the concentration of the second substrate, $\mathrm{O}_{2}$. Rapid reaction studies show the formation of an intermediate which is common to both the oxidation and inactivation pathways. This intermediate appears to be a charge-transfer complex between enzyme-reduced flavin and 2-keto-3-butynoate. It is characterized by a long-wavelength absorbing band $\left(\lambda_{\max } 600 \mathrm{~nm}\right)$ and lack of fluorescence, making it easily distinguished from
\end{abstract}

The use of acetylenic substrate analogues as specific irreversible inactivators of target enzymes was initiated by Bloch and his colleagues (Bloch, 1969), using 3-decynoyl thiolesters to inactivate $\beta$-hydroxydecanoyl thiolester dehydrase. Specificity devolved from the fact that the enzyme converts the acetylenic molecule into a conjugated allenic thiolester, the actual alkylating agent, at its active site. Subsequently, acetylenic analogues have been used to inactivate thiolase (Holland et al., 1973), plasma amine oxidase (Hevey et al., 1973), ketosteroid isomerase (Batzold and Robinson, 1975), and several pyridoxal phosphate-dependent enzymes (Abeles and Walsh, 1973; Marcotte and Walsh, 1975). In each instance carbanionic intermediates are suspected during catalysis, and covalent modification of some amino acid residue on the protein (apoprotein) is indicated.

In addition several flavoenzymes can be induced to undergo irreversible inactivation by acetylenic analogues. Pargyline ( $N$-benzyl- $N$-methylpropynylamine), long known to inhibit the flavin-linked monoamine oxidase (Hellerman and Erwin, 1968), appears to modify the FAD cofactor (Chuang et al., 1974). With $N$-dimethylpropynylamine as substrate, a covalent adduct forms at $\mathrm{N}_{5}$ of the flavin coenzyme (Maycock et al., 1976). In 1972 we reported the preliminary observation that the Mycobacterium smegmatis L-lactate oxidase is irreversibly inactivated by 2 -hydroxy-3-butynoate due to covalent

$\uparrow$ From the Department of Biological Chemistry, The University of Michigan (S.G., H.O., and V.M.), Ann Arbor, Michigan 48104, the Graduate Department of Biochemistry (Publication No. 1072), Brandeis University (A.S. and R.H.A.), Waltham, Massachusetts 02154 , and the Departments of Chemistry and Biology, Massachusetts Institute of Technology (C.T.W.), Cambridge, Massachusetts 02139. Received December 2, 1975. Supported by grants from the U.S. Public Health Service [GM 11106 (V.M.), GM 20011 (C.T.W.), 5T01GM 00212 (A.S.)] and from the National Science Foundation [GB 31952 (R.H.A.)].

$₫$ Present address: Fachbereich Biologie, University of Konstanz, Germany.

$\S$ Present address: Department of Biological Chemistry, Yamaguchi University, Ube, Japan.

\# Present address: Laboratory of Pharmacology, Harvard School of Dental Medicine, Boston, Massachusetts 02115. the subsequently formed inactivated enzyme, which has no long wavelength absorption $\left(\lambda_{\max } 318,368 \mathrm{~nm}\right)$ and which is strongly fluorescent. Inactivation is also accomplished by reaction of the reduced enzyme with 2-keto-3-butynoate. The absorbance and fluorescence characteristics of the inactivated enzyme are similar to those of a model compound, $\mathrm{C}_{4 \mathrm{a}}, \mathrm{N}_{5-}$ propano-bridged FMN bound to apolactate oxidase. That the modified chromophore of the inactivated enzyme is an adduct involving both the $\mathrm{C}_{4 \mathrm{a}}$ and $\mathrm{N}_{5}$ positions is further supported by the spectral and fluorescence changes resulting from treatment of the inactivated enzyme with borohydride.

modification of the bound FMN (Walsh et al., 1972a). This observation is universal for all the flavin-dependent $\alpha$-hydroxy acid oxidizing enzymes subsequently examined, including the membraneous D-lactate and L-lactate dehydrogenases of Escherichia coli (Walsh et al., 1972b), the L-hydroxy acid oxidase from rat kidney (Cromartie and Walsh, 1975a,b), the yeast hemeflavoprotein cytochrome $b_{2}$ (Lederer, 1974), and spinach glycolate oxidase (Jewess et al., 1975). Model studies from Hemmerich's laboratory (Zeller et al., 1972; Gartner, 1974) have shown that photoaddition of dimethylpropargylamine and flavins yields covalent adducts with structures similar to those found in the enzymatic experiments.

The ubiquitous susceptibility of this class of flavoenzymes to acetylenic inactivators suggests that understanding the mechanism of inactivation and the chemical structure of the covalent adduct to the flavin coenzymes may aid the elucidation of flavoenzyme catalytic mechanisms. In this regard, the acetylenic hydroxybutynoate is an oxidizable substrate as well as an inactivator both for the $M$. smegmatis enzyme (Walsh et al., 1972a) and for the other enzymes noted above.

In this paper we report studies on the partitioning of the acetylenic substrate between oxidation and enzyme inactivation, including stopped-flow and steady-state kinetic investigations. We also report on some of the spectroscopic and chemical properties of the modified holoenzyme and make comparison with a model compound $\mathrm{C}_{4 a}, \mathrm{~N}_{5}$-propano-bridged FMN bound to apolactate oxidase. In the accompanying paper we detail the isolation and characterization of a stabilized derivative of the inactivator-modified FMN which permits structural assignment to the inactivated holoenzyme.

\section{Experimental Procedure}

Materials and Methods. Lactate oxidase was isolated from $M$. smegmatis by the method of Lockridge et al. (1972) and the concentration of enzyme-bound FMN was determined from the extinction at $450 \mathrm{~nm}\left(10600 \mathrm{M}^{-1} \mathrm{~cm}^{-1}\right)$. Apolactate oxidase was prepared by the method of Choong et al. (1975). Reconstitution with the modified FMN (cf. below) was achieved by incubation of the apoenzyme immediately after 
preparation with an excess of the modified coenzyme at $25^{\circ} \mathrm{C}$ for $20 \mathrm{~min}$ in $0.1 \mathrm{M}$ Tris-acetate buffer, $\mathrm{pH} 7.8$. The excess of modified FMN was then removed by filtration through Sephadex G25 equilibrated with the same buffer.

DL-2-Hydroxy-3-butynoic acid was prepared by published procedures (Leonard, 1956; Verny and Vessiere, 1967). FAD was obtained from Sigma and phosphodiesterase ( Naja naja venom) from Ross Allen Reptile Institute, Silver Springs, Florida.

The optical spectra were recorded with a Cary 17 or 118 spectrophotometer at $25^{\circ} \mathrm{C}$. For the anaerobic experiments, Thunberg type cells were used. The fluorescence spectra were recorded with the fluorimeter described earlier (Casola et al., 1966). The rapid kinetics experiments were carried out at 25 ${ }^{\circ} \mathrm{C}$ with the stopped-flow apparatus of Gibson and Milnes (1964) which was modified as will be reported elsewhere. ${ }^{1}$

Chemical Synthesis of 4a,5-Propano-4a,5-dihydro-FAD and 4a,5-Propano-4a,5-dihydro-FMN. A suspension of 70 $\mathrm{mg}$ of FAD in a mixture of $5 \mathrm{ml}$ of $2 \mathrm{M}$ phosphate buffer and $5 \mathrm{ml}$ of dimethylformamide was adjusted to $\mathrm{pH} 8$ with solid potassium carbonate and flushed with nitrogen under vigorous stirring for $10 \mathrm{~min}$. Reduction of FAD was carried out by adding $200 \mathrm{mg}$ of solid sodium dithionite, the formation of reduced FAD being indicated by the appearance of an orange suspension. To this, $2.0 \mathrm{ml}$ of 1,3-dibromopropane was added, and the mixture was stirred at $4{ }^{\circ} \mathrm{C}$ under anaerobic conditions. To follow the progress of the reaction, aliquots of the mixture were adjusted to $\mathrm{pH} 5$ with glacial acetic acid, diluted with methanol-water to a concentration suitable for spectroscopic measurement, and shaken with air until complete reoxidation of the flavin ${ }^{2}$ had occurred. The formation of the product is indicated by the appearance of an absorption at $380 \mathrm{~nm}$ and disappearance of the absorption of the oxidized FAD ( $\lambda 450$ $\mathrm{nm})$. When the ratio of the absorbances at $370-450 \mathrm{~nm}$ was approximately ten, $5 \mathrm{ml}$ of water was added, and the mixture was adjusted to $\mathrm{pH} 5.5$ with acetic acid. The water phase was extracted three times with $50 \mathrm{ml}$ of chloroform, once with 50 $\mathrm{ml}$ of ether, and the crude compound purified (in batches) over two subsequent Bio-Gel $\mathrm{P}_{2}$ columns equilibrated with $0.05 \mathrm{M}$ sodium acetate buffer, $\mathrm{pH}$ 5.5. The 4a,5-propanodihydro-FAD is eluted in front of FAD, and can be recognized by its paler yellow color and lack of the fluorescence typical for oxidized flavins. Absorption spectra were $(0.1 \mathrm{M}$ phosphate buffer, $\mathrm{pH}$ 7.0; the extinction coefficients are given in brackets and are estimated from the complex with apo-D-amino acid oxidase, assuming binding of one FAD derivative per protein, error $\pm 10 \%) \lambda_{\max } 385 \mathrm{~nm}(\epsilon 6500)$, and 260 (43000); $\lambda_{\text {sh }} 310$ (14 100), and $280(34000) ; \lambda_{\min } 345 \mathrm{~nm}$ (4300). The compound is bound by apo-D-amino acid oxidase and the complex has a fluorescence emission maxima at $518 \mathrm{~nm}$; it is hydrolyzed by phosphodiesterase (cf. below). Small contaminations with compounds, in which position $\mathrm{N}(3)-\mathrm{H}$ of the flavin, ribitylor ribosyl-OH or adenine- $\mathrm{NH}_{2}$ might be alkylated, cannot be excluded. It is assumed that the apoenzyme will bind preferentially the less modified FAD model. The further chemical and spectral properties of 4a,5-propano-FAD are closely similar to those of the corresponding lumiflavin derivative, which has been described elsewhere (Ghisla et al., 1974).

4a,5-Propano-4a,5-dihydro-FMN was prepared from 4a,5-propano-4a,5-dihydro-FAD ${ }^{3}$ by hydrolysis of the latter with phosphodiesterase. A solution of the FAD derivative ( 5

D. Ballou, manuscript in preparation.

2 Abbreviations used: $F l_{\text {ox }}$, oxidized flavin: $F l_{\text {red }}$, reduced flavin.

${ }^{3}$ S. Ghisla. unpublished experiments. $\mathrm{ml}$ of $\sim 10^{-4} \mathrm{M}$ in $0.05 \mathrm{M}$ phosphate buffer, $\mathrm{pH}$ 6.5) was incubated at $25^{\circ} \mathrm{C}$ with $\mathrm{Naja}$ naja venom until the spectral changes accompanying the cleavage of the pyrophosphate bond had reached completion. This mixture was then chromatographed on a Bio-Gel $P_{2}$ column (ca. $2 \times 50 \mathrm{~cm}$ ) equilibrated with the same buffer and the purified material was frozen immediately after separation. 3-Methyl-4a,5-propano4a,5,10a,1-tetrahydrolumiflavin was prepared from 3methyl-4a,5-propano-4a,5-dihydrolumiflavin (Ghisla et al., 1974 ) by reduction with sodium borohydride: $100 \mathrm{mg}$ of the latter compound was dissolved in the minimal amount of methanol and sodium borohydride was added in small portions until the 370-nm absorption band of the starting material had disappeared. The mixture was then cooled in ice, and water was added until beginning of crystallization. The crude material (yield 70-80\%) was then recrystallized to a constant melting point $\left(234-236^{\circ} \mathrm{C}\right)$ from the same solvent. Anal. Calcd for $\left(\mathrm{C}_{17} \mathrm{H}_{22} \mathrm{~N}_{4}\right)_{2}$ (mol wt 314.38): C, 64.96; H, 7.05; N, 17.82 . Found: C, $65.02 ; \mathrm{H}, 6.83 ; \mathrm{N}, 17.81 \%$. Uv spectrum $(0.1 \mathrm{M}$ $\mathrm{KCl})$ was $\lambda_{\max } 305 \mathrm{~nm}(\epsilon 3600) ; \lambda_{\mathrm{sh}} 248 \mathrm{~nm}(\epsilon 5200)$. NMR spectrum (in $\mathrm{Me}_{2} \mathrm{SO}-d_{6}, \mathrm{Me}_{4} \mathrm{Si}$ as reference) had signals at: $8.55\left(\mathrm{~N}(1)-\mathrm{H}\right.$, one proton, broad, exchanges with $\left.{ }^{2} \mathrm{H}_{2} \mathrm{O}\right), 6.55$ (C(6)-H and $\mathrm{C}(9)-\mathrm{H}$, two protons), $4.42(\mathrm{C}(10 \mathrm{a})-\mathrm{H}, 1$ proton, broad, band narrows after exchange of $\mathrm{N}(1)-\mathrm{H}$ with $\left.{ }^{2} \mathrm{H}\right)$, 4.2-1.3 (6 protons of propano bridge, multiplet), 2.98 ( $\mathrm{N}(10)-\mathrm{CH}_{3}, 3$ protons, singlet), $2.72 \mathrm{ppm}\left(\mathrm{N}(3)-\mathrm{CH}_{3} ; 3\right.$ protons, singlet), and $2.06 \mathrm{ppm}$ (6 protons, $\mathrm{C}(7)-\mathrm{CH}_{3}$ and $\left.\mathrm{C}(8)-\mathrm{CH}_{3}\right)$. When the reduction is carried out with sodium borodeuteride, the signal at $4.42 \mathrm{ppm}$ is not present.

\section{Results and Discussion}

Kinetics of 2-Hydroxybutynoate Oxidation and Inactivation. DL-2-Hydroxy-3-butynoate is both a substrate and an irreversible inactivator of lactate oxidase (Walsh et al., 1972a). Figure 1 shows that, in the presence of $24.5 \mathrm{mM}$ DL-2-hydroxy-3-butynoate, oxygen is consumed on addition of enzyme and that oxygen consumption ceases before the oxygen supply is exhausted. Each addition of active enzyme results in further oxygen uptake before inactivation again occurs. The concentration of 2-hydroxybutynoate does not change significantly during the course of such an experiment. The addition of catalase does not result in oxygen production as would be expected if peroxide were produced in the reaction of lactate oxidase with DL-2-hydroxybutynoate. This suggests that oxygen is reduced to water, as is the case in the reaction of L-lactate and lactate oxidase. Therefore, by analogy with the normal reaction, one would expect the products in the oxidation of 2hydroxybutynoate to be 2-propynoic acid and carbon dioxide, as indicated.

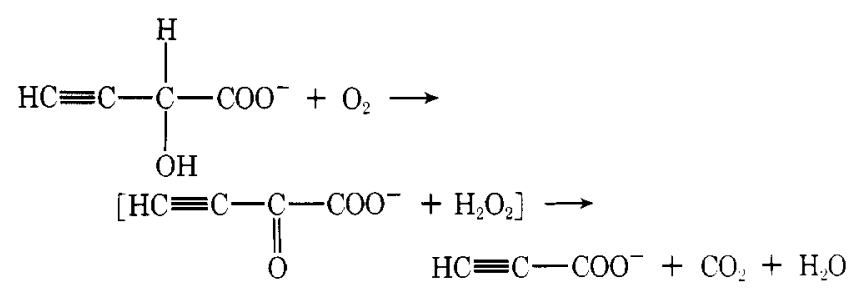

Figure 1 also shows that the number of times the enzyme turns over before inactivation is dependent on the oxygen concentration in the assay solution. The lower the concentration of oxygen the fewer the turnovers the enzyme undergoes before it is inactivated. Under anaerobic conditions, a stoichiometric amount of 2-hydroxy-3-butynoate, calculated on the assumption that only the $L$ isomer is reactive, will com- 


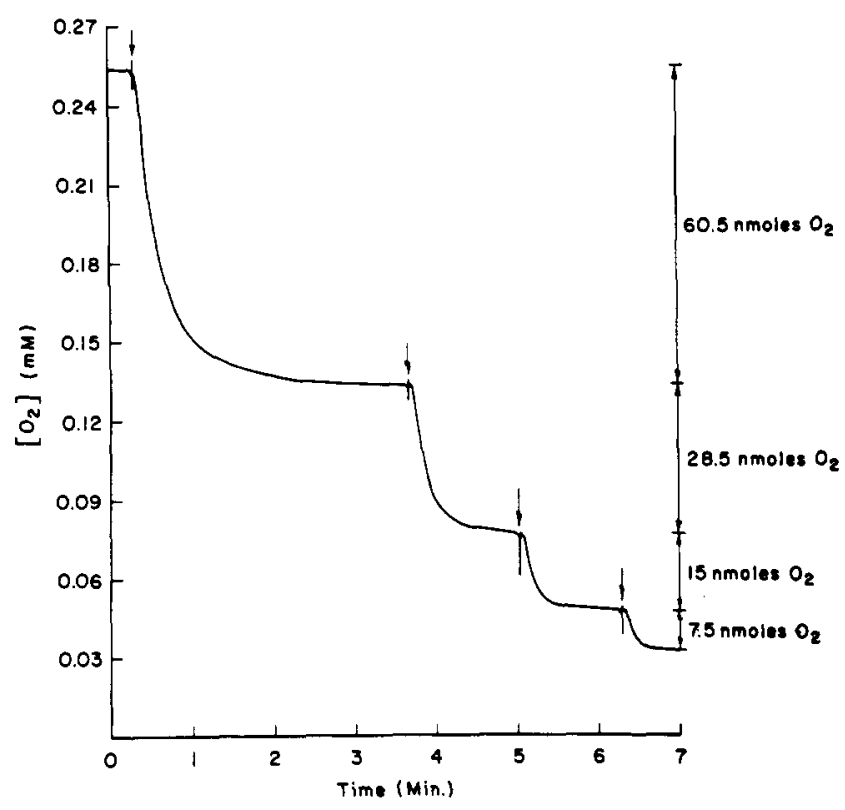

FIGURE 1: Oxygen uptake with DL-2-hydroxy-3-butynoic acid. The reaction mixture contained $24.5 \mathrm{mM}$ DL-2-hydroxy-3-butynoate in $50 \mathrm{mM}$ imidazole chloride buffer, $\mathrm{pH} 7$, and was equilibrated with air at room temperature before being placed in a $0.5-\mathrm{ml}$ oxygen electrode cell. Ten microliters of lactate oxidase $(3 \mathrm{mg} / \mathrm{ml}$; specific activity, $64 \mu \mathrm{mol} /(\mathrm{min}$ $\mathrm{mg}^{-1}$ )) was added at the points indicated by arrows. The concentration of DL-2-hydroxy-3-butynoate did not change significantly during the course of the reaction.

pletely inactivate the enzyme (Walsh et al., 1972a). Thus, inactivation and oxidation are competitive reaction paths.

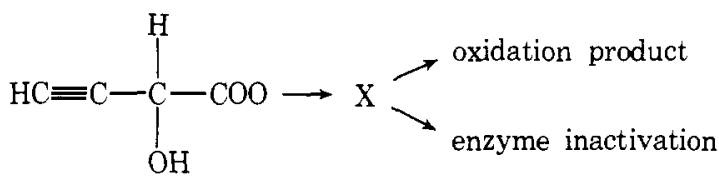

The rate of oxygen consumption with 2-hydroxy-3-butynoate is initially linear. From a plot of the reciprocal of the initial rate of oxygen uptake against the reciprocal of the substrate concentration, an apparent $K_{\mathrm{m}}$ of $1.41 \mathrm{mM}$ was obtained for DL-2-hydroxy-3-butynoate (at air saturation). This is shown in Figure 2A. In the same way, the reciprocal of the rate of inactivation of lactate oxidase (i.e., the half-time of inactivation) plotted as a function of the reciprocal of the DL-2-hydroxybutynoate concentration will allow the determination of a $K_{\text {inact }}$ for this compound. The plot shown in Figure 2B gives a value of $1.35 \mathrm{mM}$ for $K_{\text {inact. }}$ The close agreement between the values of $K_{\text {inact }}$ and $K_{\mathrm{m}}$ for DL-2-hydroxy-3-butynoate suggests that the suicide substrate is bound to the enzyme in the same way for both normal oxidation and for inactivation as one would expect if both processes occur from some common intermediate.

One can calculate the maximal velocity for DL-2-hydroxy3-butynoate acting as a substrate. The data from Figure $2 \mathrm{~A}$ indicate a $V_{\max }$, at air saturation, of $4.4 \mu \mathrm{mol} /\left(\mathrm{min} / \mathrm{mg}^{-1}\right)$ corresponding to a turnover number of $220 \mathrm{~min}^{-1}$. Comparison of this turnover value with that for L-lactate $\left(3200 \mathrm{~min}^{-1}\right)$ is complicated by the observation (Sullivan, 1968) that D isomers are strong competitive inhibitors. For instance, saturating levels of DL-lactate produce a turnover value of $250 \mathrm{~min}^{-1}$, quite comparable to that with racemic hydroxybutynoate.

From the data of Figure $2 B$ one can similarly calculate a limiting rate of inactivation, at air saturation, which is $2 \mathrm{~min}^{-1}$. As will be shown below (stopped-flow experiments), the
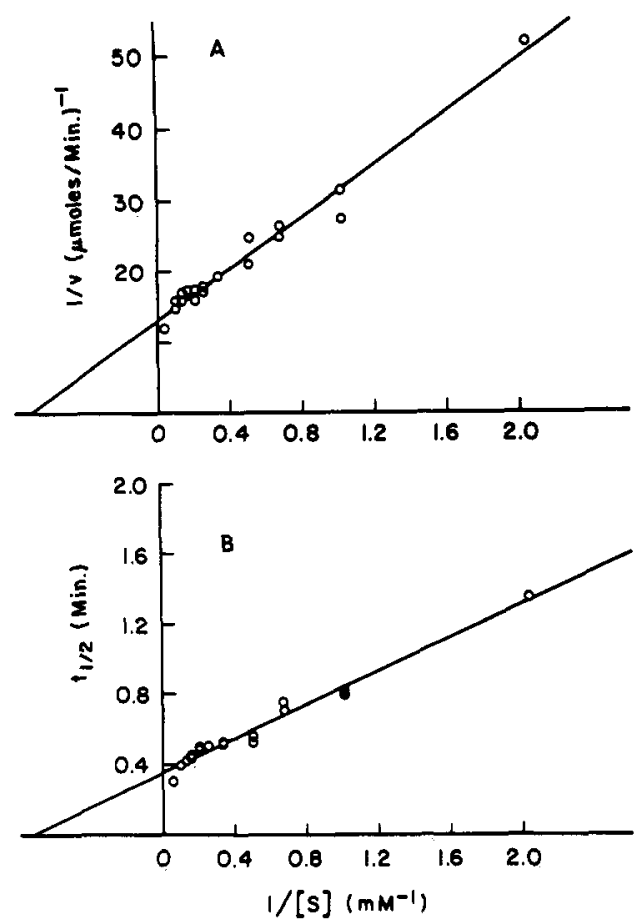

FIGURE 2: (A) Michaelis-Menten plot of the initial rate of oxygen consumption in the oxidation of DL-2-hydroxy-3-butynoate by lactate oxidase. (b) The half-life of inactivation of lactate oxidase as a function of the reciprocal of DL-2-hydroxy-3-butynoate concentration. Reactions were carried out under the same conditions as described in Figure 1 except

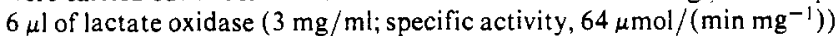
was used for each assay.

maximal rate of inactivation is considerably accelerated under anaerobic conditions. Since the observed $K_{\text {inact }}$ changes with oxygen concentration, any substantial decrease in oxygen content of the enzyme solution will lead to a faster apparent rate of inactivation. This is borne out by the data of Figures 1 and 2. In the experiments described in Figure 1, enough enzyme was used to allow convenient monitoring of substrate oxidation and resulted in substantial conversion of dissolved $\mathrm{O}_{2}$ to $\mathrm{H}_{2} \mathrm{O}$. Calculation of the number of turnovers to achieve complete enzyme inactivation in this experiment gives 30 turnovers. On the other hand in experiments providing the data of Figures $2 \mathrm{a}$ and $2 \mathrm{~b}$, less enzyme was used and less $\mathrm{O}_{2}$ consumed; now, one of every 110 turnovers results in inactivation. This number can be calculated not only from nanomoles of $\mathrm{O}_{2}$ consumed by the amount of enzyme present, but also from the maximal turnover number and the maximal $K_{\text {inact }}$ [ 220 $\left.\min ^{-1} / 2 \min ^{-1}\right)=110$ turnovers to inactivation]. This value of 110 is independent of 2-hydroxy-3-butynoate concentration under the experimental conditions, again consistent with the partitioning of some common precursor between oxidation and inactivation.

Stopped-Flow Anaerobic Studies. 1. Anaerobic Reaction of 2-Hydroxy-3-butynoate with Oxidized Lactate Oxidase. Figure 3 shows the spectral changes which occur when lactate oxidase and DL-2-hydroxy-3-butynoate are mixed under anaerobic conditions. A rapid decrease of the characteristic absorption of the oxidized enzyme occurs between 350 and 550 $\mathrm{nm}$ concomitant with the appearance and later the disappearance of a long wavelength absorption with a maximum at about $600 \mathrm{~nm}$. These spectral changes occur in three distinct phases. In the first rapid phase (0.2-s curve, Figure 3$)$, the absorbance at $460 \mathrm{~nm}$ decreases to about half of its original value and the long wavelength absorption reaches a maximum. The observed first-order rate constant for the rapid increase 


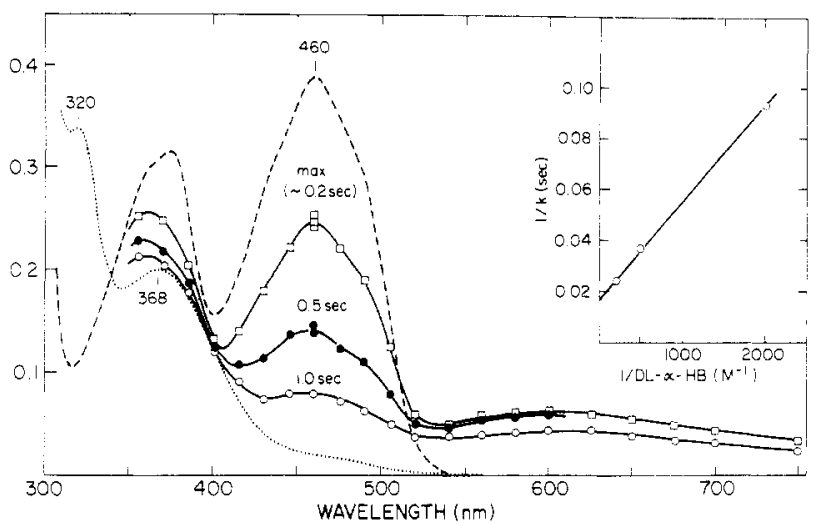

FIGURE 3: Spectral intermediates formed during the anaerobic reaction of lactate oxidase with 2-hydroxy-3-butynoate. The enzyme, $3.5 \times 10^{-5}$ $\mathrm{M}$ in $0.01 \mathrm{M}$ imidazole- $\mathrm{HCl}, \mathrm{pH} 7.0(---)$, was mixed at $25^{\circ} \mathrm{C}$ with solutions of DL-2-hydroxy-3-butynoate $\left(5 \times 10^{-3}, 2 \times 10^{-3}\right.$, and $5 \times 10^{-4}$ $M$ final concentration) in the same buffer. The curves shown, selected for illustration purposes, were obtained with $5 \times 10^{-3} \mathrm{M} 2$-hydroxy-3-butynoate: (ם) at the end of first, fast phase; $(\bullet)$ at $0.5 \mathrm{~s}$; and $(0)$ at $1.0 \mathrm{~s} .(\cdots)$ Represents the absorption at the end of the reaction and is identical with the spectrum of the inactivated enzyme. The inset shows the reciprocal plot of the first, fast rate of appearance of the long wavelength absorption measured at $580 \mathrm{~nm}$ at the concentrations of 2-hydroxy-3-butynoate given.

in absorption measured at $580 \mathrm{~nm}$ shows saturation kinetics (inset, Figure 3). The " $K_{\mathrm{m}}$ " obtained from this plot is $2.1 \mathrm{mM}$, in good agreement with the value obtained from turnover experiments. The rate constant at saturating substrate concentrations is $62 \mathrm{~s}^{-1}$, which is more than sufficiently rapid for this step to be kinetically significant in the overall reaction.

In the second phase (0.5-s curve, Figure 3 ), absorption at $460 \mathrm{~nm}$ decreases further and the long wavelength absorption stays essentially constant.

The long wavelength absorbing species present during the first two phases of the reaction probably consists of a complex of the reduced enzyme with 2-keto-3-butynoic acid. When the spectral species observed after $0.2 \mathrm{~s}$ (Figure 3 ) is corrected for the presence of approximately $50 \%$ unreacted oxidized enzyme, the resulting spectrum has a minimum at $430-450 \mathrm{~nm}$ and a maximum at $\sim 600 \mathrm{~nm}\left(\epsilon_{600} \sim 4000\right)$ (not shown). This type of spectrum is common to charge-transfer complexes of reduced forms of flavoenzymes and small molecule acceptors (Massey and Ghisla, 1974). Such intermediates having long wavelength absorptions have been observed in the reaction of oxidized lactate oxidase with L-lactate and upon anaerobic addition of pyruvate to reduced lactate oxidase (Lockridge et al., 1972). Thus, L-2-hydroxy-3-butynoate appears to behave as a normal substrate in the first phases of the reaction with lactate oxidase leading to reduction of the enzyme and oxidation of the substrate to the keto acid. The observation of a biphasic reaction between lactate oxidase and DL-2-hydroxy-3-butynoate leading to the formation of this long wavelength intermediate is not surprising. D isomers of $\alpha$ hydroxy acids are strong competitive inhibitors (Sullivan, 1968) and dissociate from lactate oxidase slowly (Massey and Ghisla, unpublished). Therefore, by analogy to the reaction of lactate oxidase with DL-lactate, the first rapid phase observed in Figure 3 probably corresponds to the reaction of the enzyme complexed with the $L$ isomer of 2-hydroxy-3-butynoate. The rate of the second phase is determined by the rate of release of the $D$ form of the substrate from its nonreactive complex with the enzyme, as indicated in Scheme I.

Following these two phases, an even slower reaction $(k=$ $1 \mathrm{~s}^{-1}$ ) leads to the disappearance of all absorption at wave-
Scheme I

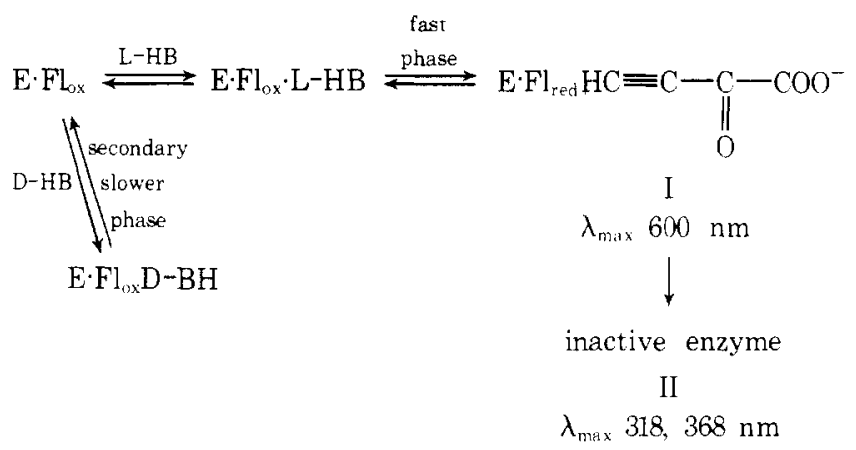

lengths greater than $520 \mathrm{~nm}$ and to the formation of a new species with maxima at 318 and $368 \mathrm{~nm}$ (Figure 3 ). The rate of appearance of this final species (compound II of Scheme I) is independent of the concentration of 2-hydroxy-3-butynoate used, again consistent with its formation from some enzyme intermediate or enzyme-keto acid complex. This last species does not have the same absorption as free reduced lactate oxidase and has been shown to represent a covalent adduct between lactate oxidase and hydroxybutynoate (Walsh et al., 1972a; Schonbrunn et al., 1976).

The absence of fluorescence of the observed long wavelength intermediate (see Figure 5 and Scheme I) is consistent with the nature of the proposed structure (I). Reduced lactate oxidase and covalent adducts of the reduced coenzyme are known to be fluorescent, whereas complexes of the reduced enzyme with pyruvate and other $\alpha$-keto acids are nonfluorescent (Ghisla et al., 1974). By contrast, the inactivated enzyme (II) formed after the disappearance of the absorption at wavelengths greater than $520 \mathrm{~nm}$ shows a strong fluorescence with a maximum at $502 \mathrm{~nm}$, providing further evidence that it is a covalent adduct of the enzyme flavin.

From the rate of formation of inactive enzyme $11,60 / \mathrm{min}$ under these anaerobic conditions, and the limiting $K_{\text {inact }}$ of $2 / \mathrm{min}$ under air saturation noted above, we might expect 30 turnovers, not 110 , before inactivation ensues. Currently we do not know the basis for the discrepancy between these values.

2. Anaerobic Reaction of 2-Ketobutynoic Acid and Reduced Lactate Oxidase. To test the hypothesis that a complex between reduced enzyme and 2-keto-3-butynoate lies on a reaction path leading to the inactivated enzyme, the experiment illustrated in Figure 4 was carried out. 2-Keto-3-butynoate is highly unstable and was therefore generated in situ from 2hydroxy-3-butynoate with lactate dehydrogenase and $\mathrm{NAD}^{+}$. Since reduced lactate oxidase cannot be inactivated by 2 hydroxy-3-butynoate (Walsh et al., 1972a), formation of a flavin inactivator adduct with reduced enzyme will be due to reaction of reduced lactate oxidase with 2-keto-3-butynoate.

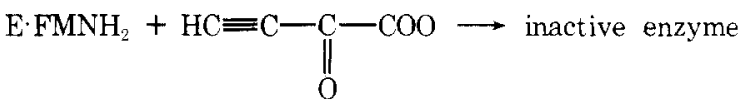

The reduction of the enzyme was carried out photochemically in a nitrogen atmosphere in the presence of oxalate as described elsewhere (Ghisla and Massey, 1975). This somewhat cumbersome method of producing reduced enzyme was used rather than reduction with the normal substrate L-lactate, to prevent complications arising from slow formation of oxidized enzyme by reversal of the equilibrium:

$$
\begin{aligned}
& \mathrm{E} \cdot \mathrm{Fl} \mathrm{ox}_{\mathrm{o}}+\mathrm{L} \text {-lactate } \rightleftharpoons \mathrm{E} \cdot \mathrm{Fl}_{\mathrm{nx}} \cdot \mathrm{L} \text {-lactate } \rightleftharpoons \\
& \mathrm{E} \cdot \mathrm{F} l_{\text {red }} \cdot \text { pyruvate } \rightleftharpoons \mathrm{E} \cdot \mathrm{Fl}_{\mathrm{red}}+\text { pyruvate }
\end{aligned}
$$

Similarly, other conventional methods of reduction $\left(\mathrm{BH}_{4}{ }^{-}\right.$, 


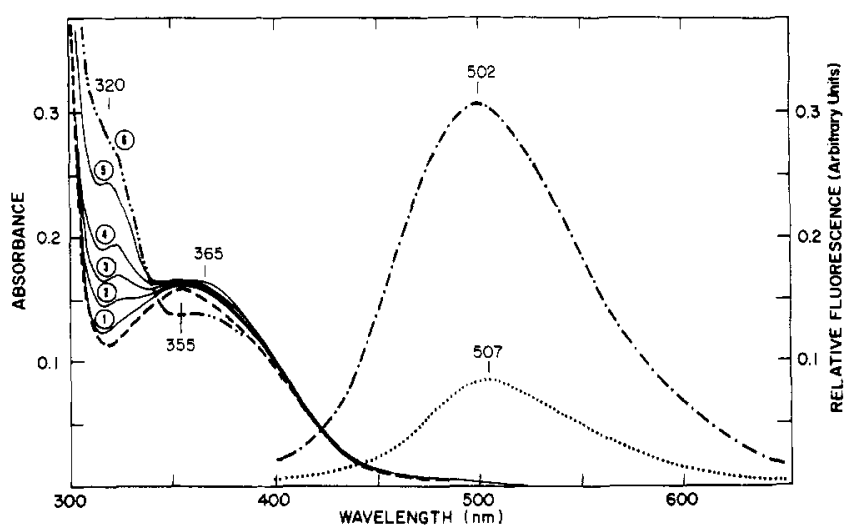

FIGURE 4: Inactivation of reduced lactate oxidase with 2-keto-3-butynoate. An anaerobic solution $(2.0 \mathrm{ml})$ containing lactate oxidase, $3.4 \times$ $10^{-5} \mathrm{M}$ in $0.01 \mathrm{M}$ imidazole- $\mathrm{HCl}, \mathrm{pH} 7.0$, lactate dehydrogenase $(0.264$ $\mathrm{mg}$ ), and $5 \times 10^{-4} \mathrm{M}$ oxalate was incubated in the dark until the spectral changes occurring upon binding of oxalate to lactate oxidase were complete $(\sim 15 \mathrm{~min})$. This solution was then illuminated until complete formation of the N(5)-carbonate adduct of the flavin, and this species was allowed to decay to form the reduced flavin-enzyme complex $\left(\sim 24 \mathrm{~h}\right.$ at $\left.4^{\circ} \mathrm{C}\right)$ : $(--)$ absorption and $(.$.$) fluorescence emission spectrum. 2-Hy-$ droxy-3-butynoate ( $30 \mu$ lof $0.8 \mathrm{M}$; final concentration, $1.2 \times 10^{-2} \mathrm{M}$ ) and $20 \mu \mathrm{l}$ of $5 \times 10^{-1} \mathrm{M} \mathrm{NAD}^{+}$(final concentration, $5.0 \times 10^{-3} \mathrm{M}$ ) were then added anaerobically, and the same amounts of reagents were added to the reference cuvette. Curves $1,2,3,4,5$, and 6 represent plots after 6 , $18,30,58,100$ and $240 \mathrm{~min}$, respectively, of incubation at $25^{\circ} \mathrm{C}$. The half-time of the reaction under these conditions is $50 \mathrm{~min} .(\cdot-\cdot)$ Represents the fluorescence emission of the inactivated enzyme excited at 370 $\mathrm{nm}$ and is corrected for the decay of the adduct (cf. text for further explanations).

$\mathrm{S}_{2} \mathrm{O}_{4}{ }^{2-}$ ) could not be used because they would also reduce $\mathrm{NAD}^{+}$or the 2-keto-3-butynoate formed in the reaction. Furthermore, photoreduction with a variety of donors yields the semiquinone rather than the fully reduced enzyme.

The rate of formation of flavin-inactivator adduct from the $\mathrm{E} \cdot \mathrm{Fl}$ red and ketobutynoate was followed spectrophotometrically by the large increase in absorption at $320 \mathrm{~nm}$ and a shift of the $355 \mathrm{~nm}$ band to $368 \mathrm{~nm}$. The formation of the adduct from reduced lactate oxidase is also characterized by a three- to sixfold increase in fluorescence emission intensity.

The formation of the inactivator-flavin adduct was found to be very slow under the conditions of Figure 4 with a halftime of reaction of $50 \mathrm{~min}$, presumably because the rate of association of reduced lactate oxidase and 2-keto-3-butynoate is very slow under the condition of indeterminately low substrate concentration present. However, this experiment nonetheless demonstrates that adduct formation can occur either from a complex of oxidized lactate oxidase and 2-hydroxy-3-butynoate or reduced lactate oxidase and 2-keto-3butynoate.

Stopped-flow Turnover Studies: Aerobic Reaction of $\alpha$ Hydroxybutynoate with Oxidized Lactate Oxidase. As discussed above, the rate of inactivation of lactate oxidase by 2-hydroxy-3-butynoate depends on the concentration of oxygen, due to a competition between oxidation of substrate (i.e., normal turnover) and inactivation. Figure 5A shows the dependence of the concentration of the long wavelength intermediate present during the course of the reaction on the concentration of oxygen. Under anaerobic conditions, $580-\mathrm{nm}$ absorption reaches a maximum at about $200 \mathrm{~ms}$. The decay of $580-\mathrm{nm}$ absorption leading to inactive enzyme is completed in less than $5 \mathrm{~s}\left(k_{\text {obsd }}=1 \mathrm{~s}^{-1}\right)$. At $1.35 \times 10^{-4} \mathrm{M} \mathrm{O}_{2}$ there is an initial burst of absorbance at $580 \mathrm{~nm}$ before a steady-state level is reached. The amount of intermediate which accumulates subsequently during the course of the reaction is con-
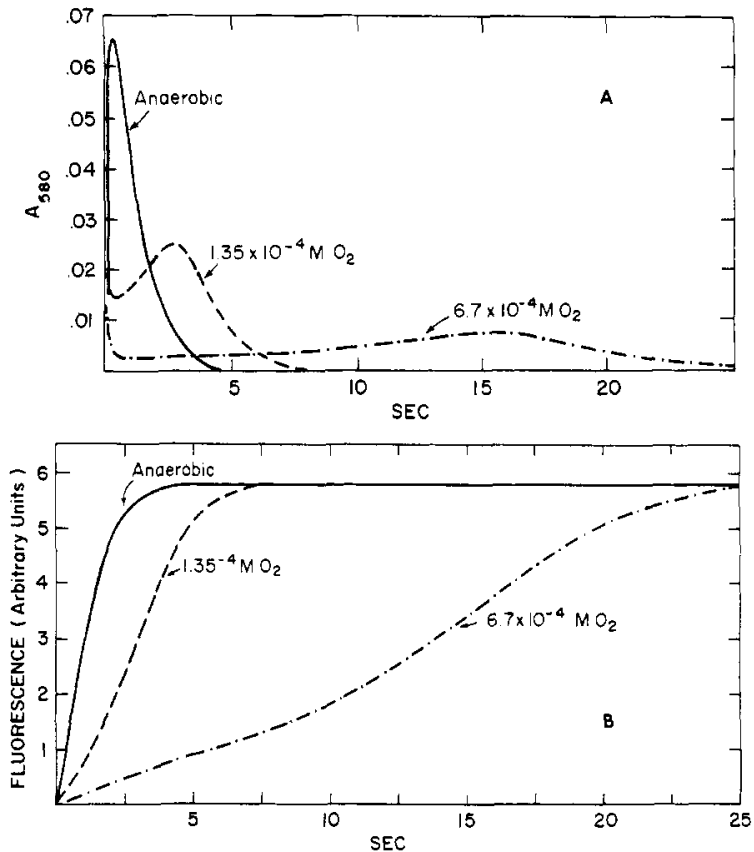

FIGURE 5: (A) Dependence of intermediate formation in the reaction of lactate oxidase with 2-hydroxy-3-butynoate on the concentration of oxygen. The enzyme, $2.0 \times 10^{-5} \mathrm{M}$ in $0.01 \mathrm{M}$ imidazole- $\mathrm{HCl}, \mathrm{pH} 7.0$, was mixed at $25^{\circ} \mathrm{C}$ with the inhibitor $\left(2 \times 10^{-3} \mathrm{M}\right)$ in the stopped-flow spectrophotometer and the absorbance changes at $580 \mathrm{~nm}$ were recorded: $(-)$ under anaerobic conditions; (- - ) in the presence of $1.35 \times 10^{-4}$ $\mathrm{MO}_{2} ;(--)$ in the presence of $6.7 \times 10^{-4} \mathrm{MO}_{2}$. (B) Formation of the inactivated lactate oxidase by 2 -hydroxy-3-butynoate as followed by the fluorescence emission of the inactivated enzyme. Conditions are as in Figure 5A. The observed fluorescence was excited at $370 \mathrm{~nm}$.

siderably less than under anaerobic conditions; its concentration reaches a maximum only after about $3 \mathrm{~s}$. At still higher oxygen concentrations $\left(6.7 \times 10^{-4} \mathrm{M}\right)$ a steady-state concentration of intermediate is maintained for up to $15 \mathrm{~s}$ (after an initial burst) and the maximal concentration of the intermediate found is only about $14 \%$ of that observed under anaerobic conditions.

When formation of the inactivated enzyme is followed by the appearance of its characteristic fluorescence (Figure 5B), a similar dependence of the rate of adduct formation on the concentration of oxygen is observed; i.e., the rate of appearance of fluorescence and the rate of disappearance of the $580-\mathrm{nm}$ absorbing intermediate are closely similar. This behavior is kinetically consistent with the reaction leading to inactivation and the reaction with oxygen arising from the same intermediate or a species in rapid equilibrium with it as shown in Scheme II.

\section{Scheme II}

$$
\begin{aligned}
& \mathrm{E} \cdot \mathrm{Fl}_{\mathrm{ox}}+\mathrm{HB} \rightleftharpoons \mathrm{E} \cdot \mathrm{Fl}_{\mathrm{ox}} \cdot \mathrm{HB} \stackrel{-\alpha \mathrm{H}^{+}}{\rightleftharpoons} \\
& \mathrm{X} \rightleftharpoons \mathrm{E} \cdot \mathrm{Fl}_{\mathrm{red}} \mathrm{KB} \rightleftharpoons \mathrm{E} \cdot \mathrm{Fl}_{\mathrm{red}}+\mathrm{KB} \\
& i^{\prime} \therefore \lambda_{\max } \\
& \mathrm{E}_{\text {inactive }} \quad \mathrm{E} \cdot \mathrm{Fl}_{o x}+\mathrm{H}_{2} \mathrm{O}+\mathrm{CO}_{2}+\mathrm{HC} \equiv \mathrm{C} \cdot \mathrm{COO}^{-} \\
& \lambda_{\max } 368,320 \mathrm{~nm}
\end{aligned}
$$

where<smiles>[B]C=CC(=O)C(=O)C(=O)[O-]</smiles> 


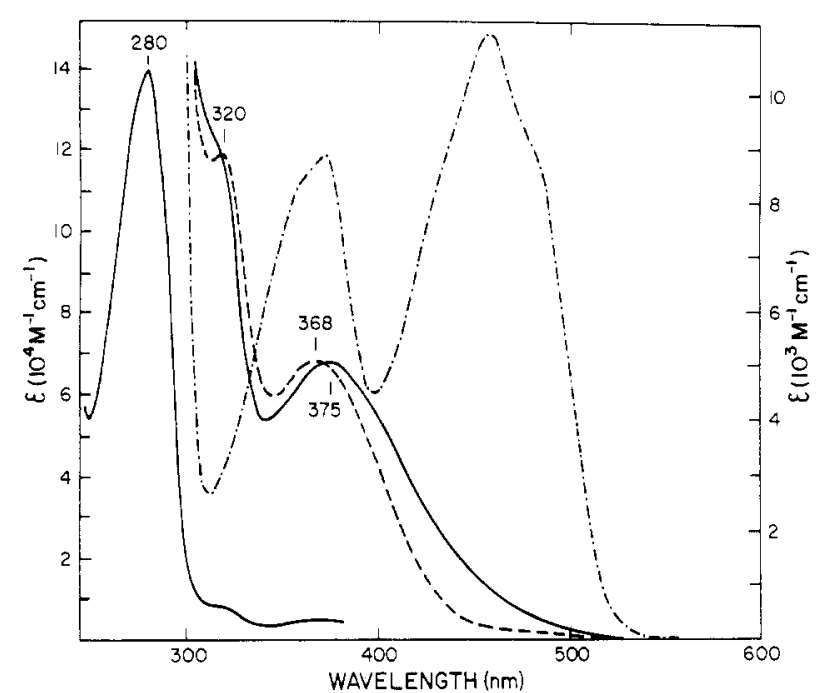

FIGURE 6: Spectral comparison of lactate oxidase after modification of the coenzyme with 2-hydroxy-3-butynoate (- - ); with 4a,5-propano-4a,5-dihydro-FMN bound to apolactate oxidase (-).) Shows the absorption of the oxidized enzyme for comparison.

This scheme is consistent with the anaerobic studies which showed that flavin adduct can be formed from either oxidized enzyme and 2-hydroxy-3-butynoate or reduced enzyme and 2-keto-3-butynoate.

Spectral Properties of Inactivated Lactate Oxidase. The absorption spectrum of the inactivated enzyme is clearly different from the spectrum of oxidized or reduced lactate oxidase (Figures 3 and 4). It is characterized by absorption bands at 320 and $368 \mathrm{~nm}$ and a strong fluorescence emission with a maximum at $502 \mathrm{~nm}$. When these spectral properties are compared with those of a series of reduced flavoproteins and model compounds (Ghisla et al., 1974), it appears that the flavin inactivator adduct formed on the enzyme is probably a 4a,5-dihydroflavin derivative. Covalent derivatives of 1,5dihydroflavin are characterized by a single absorption band in the near uv centered around $350 \mathrm{~nm}$ in free solution, whereas the 4a,5-dihydroflavin chromophore has two bands of varying relative intensity at wavelengths greater than $300 \mathrm{~nm}$. In particular, a reduced flavin model compound carrying a $C_{3}$ bridge between the $\mathrm{C}_{4 \mathrm{a}}$ and $\mathrm{N}_{5}$ positions has a characteristic spectrum in solution which is very similar to the spectrum of inactivated lactate oxidase; it is moderately fluorescent at ambient temperatures and highly fluorescent when immobilized in a rigid medium at low temperature $(77 \mathrm{~K}$; Ghisla et al., 1974). When the corresponding derivative of FMN $\left(\mathrm{C}_{4 a}, \mathrm{~N}_{5-}\right.$ propanodihydro-FMN) shown below is bound to apolactate oxidase, the complex obtained has a maximum absorption of $375 \mathrm{~nm}$, a pronounced shoulder at $315 \mathrm{~nm}$, a fluorescence emission maximal at $530 \mathrm{~nm}$, and an excitation spectrum which closely follows the absorption spectrum (Figure 6).

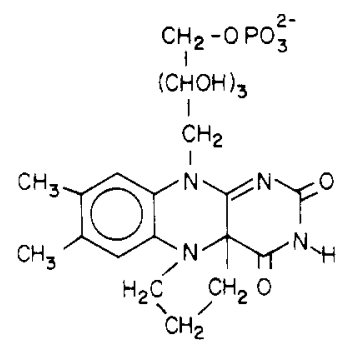

While the fluorescence and the absorption maxima of this enzyme-bound derivative do not coincide exactly with that of

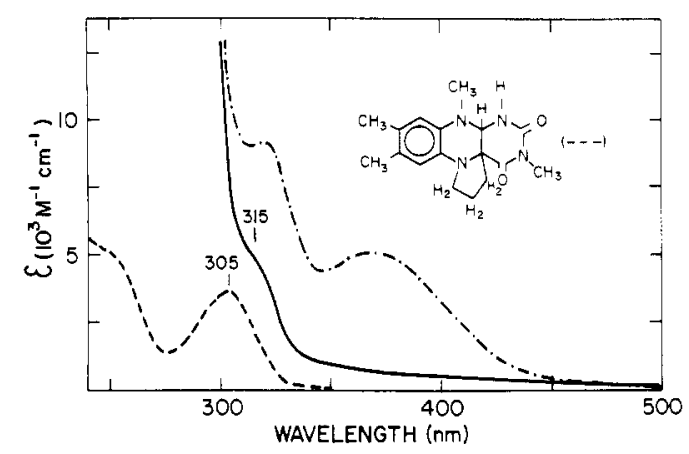

FIGURE 7: Reaction of the 2-hydroxy-3-butynoate-inactivated lactate oxidase with sodium borohydride. The enzyme $\left(1.0 \mathrm{ml} ; 4.1 \times 10^{-5} \mathrm{M}\right)$ was inactivated as described in Experimental Procedure and then passed through a short $\mathrm{G} 25$ column equilibrated with a buffer containing $10^{-2}$ $M$ each of imidazole, Tris, and pyrazine and $4 \times 10^{-2} \mathrm{M} \mathrm{Cl}^{-}, \mathrm{pH} 7.0$ $(\cdot-)$. To this solution at $25^{\circ} \mathrm{C}$ were added aliquots (ca. $0.5 \mathrm{mg}$ ) of solid sodium borohydride over a period of $20 \mathrm{~min}$ until the absorption decrease at $370 \mathrm{~nm}$ was completed. A trace of 1 -octanol was added to prevent excessive foaming. The $\mathrm{pH}$ of the solution at the end of reaction was $\sim 9(-)$. (- - ) Represents for comparison the spectrum of the model compound 3-methyl-4a,5-propano-4a,5, 10a, 1-tetrahydrolumiflavin (cf. structure), in $0.1 \mathrm{M} \mathrm{KCl}$, at the same concentration.

the hydroxybutynoate-inactivated enzyme, their properties are remarkably similar, particularly in view of previous findings that the absorption and fluorescence characteristics of reduced flavins and flavoproteins are highly dependent on the chemical nature of substituents, steric factors, and solvent or protein environment. It should be noted that the absorption spectrum of the inactivated enzyme and that of the $\mathrm{C}_{4 a}, \mathrm{~N}_{5}$ propanodihydro-FMN bound to apolactate oxidase are also similar to those of a $\mathrm{C}_{4 a}, \mathrm{~N}_{5}$ cyclic lumiflavin derivative obtained by Zeller et al. (1972) by photochemical reaction of lumiflavin with propargylamines. These spectral properties suggest that the modified flavin of hydroxybutynoate-inactivated lactate oxidase is a derivative of the $4 a, 5$-dihydroisoalloxazine chromophore and that it probably contains a bridge between the $\mathrm{C}_{4 \mathrm{a}}$ and the $\mathrm{N}_{5}$ positions. The properties of the chromophore do not, of course, provide information on how the inactivator has added to form such a cyclic derivative. This problem is considered further in the accompanying paper (Schonbrunn et al., 1976).

Properties and Reactions of the Inactivated Lactate Oxidase. The inactivated lactate oxidase was found to undergo slow spectral changes subsequent to its formation. At $\mathrm{pH} 7$, and $25^{\circ} \mathrm{C}$, the absorption of the modified enzyme decreases by $50 \%$ over a period of $24 \mathrm{~h}$ and leads to a rather featureless absorption characterized by shoulders at 320 and $370 \mathrm{~nm}$ (not shown). Concomitantly the fluorescence emission intensity decreases to $20 \%$ of the original value, whereas the emission maximum remains unchanged and the excitation spectrum follows the absorption spectrum. The rate of this decay, when followed by the changes in fluorescence, is strongly dependent on the $\mathrm{pH}$ and has an apparent minimum at $\mathrm{pH} 6.5$.

From these observations it appears that the modified flavin is unstable and undergoes undetermined chemical modifications while bound to the apoenzyme. No stabilization was observed on reaction of the inactivated enzyme with $\mathrm{NH}_{2} \mathrm{OH}$, hydrazines, $\mathrm{I}_{2}$, or $\mathrm{CN}^{-}$. On the other hand, when it is reacted with $\mathrm{BH}_{4}^{-}$under aerobic or anaerobic conditions, its fluorescence emission disappears completely and its two-banded absorption spectrum at $\lambda>300 \mathrm{~nm}$ is reduced to a featureless spectrum with a shoulder at $315 \mathrm{~nm}$ (Figure 7). It should be emphasized that simple 1,5-dihydroflavin chromophores do not react with $\mathrm{BH}_{4}-$ free in solution (Müller et al., 1969) or 
when bound to various apoproteins (Massey et al., 1968) and that oxidized flavins react with $\mathrm{BH}_{4}{ }^{-}$to yield (as well as 1,5-dihydroflavin) fluorescent species with absorption maxima in the 380-410 nm region, and which are shown to have undergone reduction at the $\mathrm{C}(4)=0$ function (Müller et al, 1969). On the other hand, the reaction observed with the enzyme could be simulated with the 4a,5-dihydro-4a,5-substituted flavin model 4a,5-dihydro-4a,5-propano-3-methyllumiflavin which, when reacted with $\mathrm{BH}_{4}-$ in methanol, yields a nonfluorescent species characterized by an absorption maximum at $305 \mathrm{~nm}$ (Figure 7). Such absorption spectra are typical of substituted phenylenediamines (Dudley and Hemmerich, 1967). The structure of the product (cf. structure, Figure 7) was confirmed by elemental analysis and NMR spectroscopy (cf. Experimental Procedure for further details). These results suggest the probable presence of the same chromophore for the $\mathrm{BH}_{4}{ }^{-}$-treated inactivated enzyme and the model and substantiated the assumption that the primary product obtained upon reaction of the enzyme with 2-hydroxy-3-butynoate has a 4a,5-dihydroflavin structure and that the subsequent $\mathrm{BH}_{4}{ }^{-}$reaction leads to reduction of the $1 \mathrm{a}-$ $\mathrm{N}(1)$-azomethine double bond of the coenzyme to form a

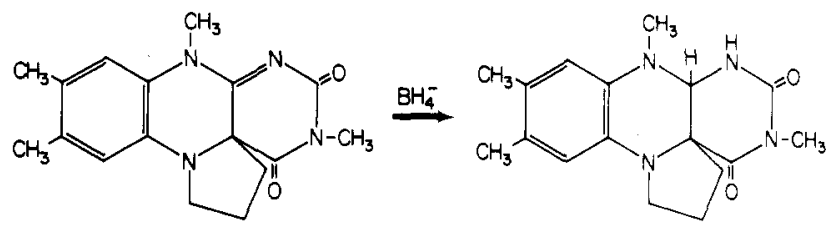

4a,5,10a, 1-tetrahydroflavin species. Further evidence for the validity of this conclusion is presented in the accompanying paper.

References

Abeles, R. H., and Walsh, C. T. (1973), J. Am. Chem. Soc. 95, 6124 .

Batzold, F. H., and Robinson, C. H. (1975), J. Am. Chem. Soc. 97, 2576.

Bloch, K. (1969), Acc. Chem. Res. 2, 193.

Casola, L., Brumby, P. E., and Massey, V. (1966), J. Biol. Chem. 241, 4977.

Choong, Y. S., Shepherd, M. G., and Sullivan, P. A. (1975), Biochem. J. 145, 37.

Chuang, H. Y. K., Patek, D. R., and Hellerman, L. (1974), J. Biol. Chem. 249, 2381 (and literature cited therein).
Cromarti, T. C., and Walsh, C. T. (1975a), Biochemistry 14, 2588.

Cromarti, T. C., and Walsh, C. T. (1975b), Biochemistry 14, 3482 .

Dudley, K. H., and Hemmerich, P. (1967), J. Org. Chem. 32, 3049.

Gartner, B. (1974), Ph.D. Thesis, University of Konstanz, West Germany.

Ghisla, S., and Massey, V. (1975), J. Biol. Chem. 250, 577.

Ghisla, S., Massey, V., Lhoste, J. M., and Mayhew, S. G. (1974), Biochemistry 13, 589.

Gibson, Q. H., and Milnes, L. (1964), Biochem. J. 91, 161.

Hellerman, L., and Erwin, V. G. (1968), J. Biol. Chem. 243, 5234.

Hevey, R. L., Babson, J., Maycock, A. L., and Abeles, R. H. (1973), J. Am. Chem. Soc. 95, 6125.

Holland, P. C., Clark, M. G., and Blaxham, D. P. (1973), Biochemistry 12, 3309.

Jewess, P. J., Kerr, M. W, and Whitaker, D. P. (1975), FEBS Lett. 53, 292.

Lederer, F. (1974), Eur. J. Biochem. 46, 393.

Leonard, N., Ed. (1956), Org. Synth. 36, 3.

Lockridge, O., Massey, V., and Sullivan, P. A. (1972), J. Biol. Chem. 247, 8097.

Marcotte, P., and Walsh, C. T. (1975), Biochem. Biophys. Res. Commun. 62, 677

Massey, V., Curti, B., Muller, F., and Mayhew, S. G. (1968), J. Biol. Chem. 243, 1339.

Massey, V., and Ghisla, S. (1974), Ann. N.Y. Acad. Sci., 227, 466 (and literature cited therein).

Maycock, A., Abeles, R. H., Singer, T. P., and Salach, J. I. (1976), Biochemistry (in press).

Müller, F., Massey, V., Heizmann, C., Hemmerich, P., Lhoste, J. M., and Gould, D. C. (1969), Eur. J. Biochem. 9, 392.

Schonbrunn, A., Abeles, R. H., Walsh, C. T., Ghisla, S., Ogata, H., and Massey, V. (1976), Biochemistry, the following paper in this issue.

Sullivan, P. (1968), Biochem. J. 110, 363.

Verny, M., and Vessiere, R. (1967), Bull. Soc. Chim. Fr., 2210.

Walsh, C. T., Abeles, R. H., and Kaback, H. R. (1972b), J. Biol. Chem. 247, 7858 .

Walsh, C. T., Schonbrunn, A., Lockridge, O., Massey, V., and Abeles, R. H. (1972a), J. Biol. Chem. 247, 6004.

Zeller, E. A., Gartner, B., and Hemmerich, P. (1972), Z. Naturforsch, B 27, 1050. 